\title{
Bem-Estar Subjetivo de Imigrantes
} Senegaleses

\section{Jaqueline de Quadros Dill Lague, Shalimar Gallon e Priscila Sardi Cerutti}

\section{RESUMO}

O Bem-Estar Subjetivo (BES) é a temática que se dedica a compreender como as pessoas avaliam a satisfação em suas vidas, a qual considera aspectos pessoais, vivências, valores e expectativas. Assim, investigar os aspectos que influenciam o BES dos imigrantes pode contribuir com sua melhor adaptação ao novo país. Nesse sentido, esta pesquisa teve como objetivo descrever o BES de imigrantes senegaleses por meio de uma pesquisa qualitativa exploratória. A coleta de dados foi realizada por meio de um grupo focal com imigrantes senegaleses e entrevista semiestruturada com gestores desses imigrantes. Para a análise dos dados, utilizou-se a análise de conteúdo. Nos resultados, identificou-se que as categorias que afetam no sentimento de BES dos imigrantes senegaleses são elementos econômicos e culturais, expectativas e emoções. Estes resultados contribuem com o avanço científico por mostrar como ocorre a relação entre o trabalhador imigrante e a empresa em que ele está inserido, mostrando uma vertente social e psicológica dessa realidade vivenciada pelos imigrantes no Brasil.

Palavras-Chave: bem-estar subjetivo; qualidade de vida; imigração.

\section{Subjective Well-Being of Senegalese Immigrants}

\section{ABSTRACT}

Subjective well-being is the theme that is dedicated to understanding how people evaluate satisfaction in their lives. This area considers personal aspects, experiences, values, expectations. Investigating aspects that influence the well-being of immigrants can contribute to their better adaptation to the new country. To describe the subjective well-being of Senegalese immigrants is the aim of this research. The qualitative exploratory cross-sectional approach was adopted. The means of investigation for data collection was the focus group with Senegalese immigrants and, posteriorly, a semi-structured interview with the managers of these immigrants. For the analysis of the data, the content analysis was used in order to prevent possible distortions of the application of a single method. In the results, it was identified that the categories that affect the subjective well-being of the Senegalese immigrants are, in general, economic and cultural elements, expectations and emotions. These results contribute to the scientific advance by showing how the relationship between the immigrant worker and the company in which he/she is inserted occurs, showing a social and psychological aspect of this reality experienced by some immigrants in Brazil.

Keywords: subjective well-being; quality of life; immigration.
Recebido em: 01/03/2018 Revisado em: 24/07/2018 Aprovado em: 13/09/2018

Check for updates

Jaqueline de Quadros
Dill Lague iD,
Faculdade Meridional - IMED, Brasil
Mestra em Administração, Faculdade
Meridional - IMED, Brasil
jaqueline.lague@gmail.com
Shalimar Gallon iD,
Faculdade Meridional - IMED, Brasil
Doutora em Administração,
Universidade Federal do Rio Grande
do Sul, Brasil
shalimargallon@gmail.com
Priscilacerutti@yahoo.com.br
Faculdade Meridional - IMED, Brasil
Mestra em Administração, Faculdade
Meridional - IMED, Brasil
Prila Sardi Cerutti iD,




\section{Introdução}

Em 2010, imigrantes caribenhos começaram a chegar, ao Brasil, devido aos desastres naturais ocorridos em seus países. As dificuldades econômicas enfrentadas pelos africanos fizeram com que, a partir de 2014, eles viessem em busca de oportunidades de trabalho, de melhores condições econômicas e sociais (Zamberlam, Corso, Cimadon, \& Bocchi, 2014). Outro fluxo migratório recebido recentemente pelo Brasil origina-se do continente asiático, devido à guerra civil gerada pelo Estado Islâmico, motivo pelo qual imigrantes, principalmente da Síria, tentam refúgio em diversos países, inclusive no Brasil (G1, 2015).

Esse contexto mostra que o fenômeno migratório vem ganhando destaque nos últimos vinte anos, mesmo sendo um comportamento humano detectado desde os primeiros ancestrais (Schrover, 2009). O Alto Comissariado das Nações Unidas para Refugiados (ACNUR) mostra que, desde abril de 2015, os fluxos de emigrantes abrangem 59,2 milhões de pessoas que partiram em busca de abrigo principalmente em terras europeias (Acnur, 2015). No Brasil, até 2015, foram abrigados e reconhecidos como refugiados cerca de 28.670 estrangeiros (Acnur, 2016).

Dados compilados do Instituto Brasileiro de Geografia e Estatística (IBGE, 2010) indicam que o estado do Rio Grande do Sul (RS) é o quarto estado do país que mais acolhe imigrantes, ficando atrás apenas dos estados de São Paulo, Rio de Janeiro e Paraná. Esses estados acolheram, em 2010, 63,8\% do total de imigrantes. O Rio Grande do sul é um dos estados brasileiros que mais recebe imigrantes, pois eles vêm em busca de oportunidades de trabalho na indústria alimentícia, por saberem fazer o abate halal (abate de animais segundo as leis da religião islâmica). Além disso, o Estado apresenta o maior índice de exportação de carne de frango para países de origem islâmica (Zamberlam et al., 2014). De modo geral, o Brasil recebe imigrantes de todo o continente africano, o que propicia o estudo sobre questões relacionadas ao trabalho para imigrantes senegaleses.

Para os imigrantes conseguirem permanecer no país, além de um comportamento correto, precisam ter vínculo empregatício com registro na carteira de trabalho, sendo esses os critérios exigidos para renovação do visto temporário de permanência. Zamberlam et al. (2014) explicam que o processo de contratação costuma ocorrer dentro da legalidade com registro em carteira de trabalho. Os imigrantes recebem os mesmos benefícios e remunerações dos brasileiros, no entanto, há relatos de exploração desta mão de obra. Os citados autores expõem a realidade vivenciada pelos imigrantes, pois precisam trabalhar muito para conseguir seu sustento e o de seus familiares, bem como para quitar as dívidas contraídas no processo migratório. Os referidos autores fazem uma analogia com a fragilidade experienciada no período da escravidão, quando havia servidões por dívidas, jornadas exaustivas, trabalhos forçados e vivência em ambientes degradantes.

Esse fenômeno requer o entendimento sobre o papel do trabalho na vida desses indivíduos, pois eles procuram melhores oportunidades em outros países, deixando para trás familiares, esposas, filhos, amigos e a própria 
cultura. Ademais, esses imigrantes assumem um compromisso com seu país e seus familiares, visto que, algumas vezes, eles são a única fonte de renda da família, o que os leva a terem que trabalhar em mais de um lugar para conseguir seu sustento e mandar dinheiro para o país de origem (Dill, Anese, Severo, \& Costa, 2015).

A realidade desses imigrantes geralmente é desconhecida pela maioria dos nativos do país que os acolhe, apenas se percebem pessoas diferentes andando pelas ruas, falando outro idioma, o que é motivo de estranheza e curiosidade. Frequentemente eles são tratados pelo poder público e mídia como invasores, ilegais, desocupados e usurpadores de postos de trabalho (Zamberlam et al., 2014; Espeiorin, 2014). São tidos também como doentes e responsáveis pela transmissão de doenças, como o ebola (Zamberlam et al., 2014). A falta de centralidade decisória em questões migratórias na esfera federal faz com que estados e municípios sintam-se descomprometidos em acolher e incluir os imigrantes (Zamberlam et al., 2014).

Ademais, ainda há preconceito por parte de alguns brasileiros e isso leva tais imigrantes a enfrentarem a discriminação social devido à cor de sua pele (Fernandes \& Castro, 2014). As dificuldades enfrentadas em sua terra natal, os desafios vencidos na trajetória até o Brasil, a deficiência na comunicação em português, a inserção nas cidades brasileiras, no trabalho e na sociedade, aliados às desavenças existentes entre os poderes municipais, estaduais e federal, podem influenciar o bem-estar desses indivíduos (Costa \& Gelmino, 2012), negativa e positivamente. O Bem-Estar Subjetivo (BES) é influenciado por inúmeros fatores, quer de caráter intrínseco, que advém do próprio indivíduo, quer de caráter extrínseco, relacionado ao ambiente (Woyciekoski, Stenert, \& Hutz, 2012).

Para tanto, o fenômeno de imigração requer o entendimento sobre o papel do trabalho na vida desses indivíduos, visto que muitos deles procuram melhores oportunidades de trabalho em outros países e a fazem sem a presença do suporte familiar. Neste contexto, questiona-se: quais os fatores que influenciam o BES no trabalho de imigrantes senegaleses? Sendo assim, a presente pesquisa objetiva descrever o BES de imigrantes senegaleses a fim de compreender a realidade social e psicológica dos imigrantes senegaleses no Brasil e contribuir para o avanço do conhecimento científico.

Frente a esse contexto, o presente estudo justifica-se visto que as pesquisas sobre imigração africana no Brasil se desenvolvem sob duas vertentes: a imigração forçada, relacionada aos tempos da escravatura, e a contemporânea. Especificamente sobre a imigração senegalesa encontram-se pesquisas relacionadas à dinâmica migratória, inclusão social, inclusão no mercado de trabalho, cultura organizacional e aculturação. Estudos sobre o BES são encontrados predominantemente em abordagens quantitativas.

As próximas seções exploram os conceitos e estudos sobre o BES, satisfação geral com a vida, afetos positivos e afetos negativos. Em seguida, apresentam-se os procedimentos metodológicos da pesquisa, a análise e discussão dos resultados e, por fim, as considerações finais. 


\section{Bem-estar Subjetivo}

Não é recente a atenção dispensada ao BES, encontrando-se evidências desde a Grécia antiga, pela filosofia, quando Aristóteles tentava decifrar o enigma da felicidade (Siqueira \& Padovam, 2008). Na contemporaneidade, pesquisadores dedicam-se a evidenciar cientificamente o BES, tornando o tema bastante discutido e aplicado na compreensão de diversos fatores psicológicos que integram o conceito de vida saudável.

A história do BES (Quadro 1) caracteriza-se por ser abrangente e difusa. Diversas áreas abordaram diferentes termos e designações ao estudar o BES, os quais, mesmo tendo alguma similaridade, não podem ser tratados como sinônimos (Andrews \& Robinson, 1991; Campbell, Converse, \& Rogers, 1976; George, 1981; Horley, 1984). O consenso entre os conceitos relacionados à temática ainda não ocorreu, embora há tempos venha sendo sugerido por pesquisadores (Diener, 1984).

Quadro 1. História e evolução do BES

\begin{tabular}{lll}
\hline Evolução conceitual & \multicolumn{1}{c}{ Período } & \multicolumn{1}{c}{ Características } \\
\hline 1. Herança sócio histórica & Século XVIII & Desenvolvimento pessoal e felicidade \\
1. Distinção conceitual & Década de 1960 & Evolução de bem-estar material para bem-estar global \\
2. Herança sócio histórica & Década de 1970 & Promoção da saúde física e mental, melhor estilo de vida \\
2. Distinção conceitual & Década de 1980 & Difusão conceito de bem-estar e BES \\
3. Herança sócio histórico & Década de 1990 & Saúde mental e psicologia positiva \\
3. Distinção conceitual & Século XXI & BES: afetos e cognição \\
\hline
\end{tabular}

Fonte: Adaptado de Galinha e Ribeiro (2005).

O BES é a área da ciência que visa compreender quais os critérios utilizados pelas pessoas para avaliar sua vida (Diener, 1996), pensando o que a torna boa e desejável (Albuquerque \& Tróccoli, 2004; Cachioni et al., 2017). Pode ser denominado de outras formas como: felicidade, satisfação, estado de espírito e afeto positivo. A definição desses conceitos ainda está em desenvolvimento, o que dificulta sua investigação. O BES é considerado por alguns teóricos como uma avaliação subjetiva da qualidade de vida (Albuquerque \& Tróccoli, 2004).

Simultâneo ao desenvolvimento sociológico do conceito do BES, a saúde passou a ser conceituada como promoção de estilo de vida. O conceito de bem-estar associou-se à saúde com enfoque na saúde mental (Terris, 1975; O'Donnel, 1986). Surgiu, então, o modelo biopsicossocial que permitiu abordar a saúde de forma holística, pois já se falava na multicausalidade de doenças. Fatores tidos como macrossociais, tais como culturas diferentes; eventos extremos como guerras e desastres ambientais; falta de suporte social; ambientes adversos e outros fatores estressantes contribuem para o desencadeamento de doenças psiquiátricas (Saraceno, 1995).

A psicologia positiva pode ser considerada a nova disciplina das áreas humanas e sociais, devido à sua intensa repercussão e à demanda de estudos no meio científico (Diener \& Ryan, 2009; Snyder \& Lopez, 2009). Ainda, Ryff e Keyes (1995) apresentam um modelo multidimensional de bem-estar, contendo seis componentes da psicologia positiva: autoaceitação, 
crescimento pessoal, objetivo e significado de vida, relação positiva com outros, domínio de ambiente e autonomia. Esse novo domínio visa relatar experiências subjetivas que envolvam bem-estar, contentamento, satisfação com o passado, felicidade no presente e desejo de otimismo para o futuro (Seligman \& Csikszentmihalyi, 2000). Essa área do conhecimento investiga as temáticas relacionadas ao BES, como gratidão, felicidade, otimismo, esperança, virtudes e resiliência (Bradburn, 1969).

Embora haja certa confusão em definir a natureza de bem-estar e de felicidade, por serem tratados como idênticos em alguns construtos, o primeiro é um termo mais preciso e o segundo um termo mais corriqueiro (Diener \& Ryan, 2009). A felicidade pode ser dividida em três categorias: (i) felicidade relacionada ao controle da vida, aproximando-se ao conceito de eudaimonia de Aristóteles, na qual o indivíduo atingiria tal crescimento psicológico de 'felicidade aprendida' e isto elevaria a profunda sensação de satisfação, com menos dependência de recompensas externas (Csikszentmihalyi, 1999); (ii) felicidade relacionada ao estado, concebida como um estado emocional de 'estar feliz' influenciado pela experiência de situações positivas e negativas da vida (Glatzer, 1987); e (iii) felicidade como traço de 'ser feliz', por serem emoções momentâneas influenciadas por fatores situacionais, ligados à personalidade do indivíduo (Diener \& Diener, 1996).

Sobreposto à inicial crise conceitual do BES estabeleceu-se consenso apenas quanto ao conceito ser composto por uma dimensão cognitiva, por meio de avaliação em termos de satisfação com a vida e por uma dimensão emocional, mediante emoções positivas ou negativas expressas em termos globais de felicidade (Galinha \& Ribeiro, 2005). Mesmo que as dimensões apareçam separadas, permanecem correlacionadas, pois o BES engloba vários fenômenos como respostas emocionais, satisfação e julgamento global com a vida. Ele exige, porém, que cada construto, mesmo correlacionado, seja avaliado isoladamente (Diener, Suh, Lucas, \& Smith, 1999).

A escala Subjective Well-Being Scale (SWBS) desenvolvida por Lawrence e Liang (1988) é frequentemente utilizada para medir a percepção de vida tida pelo próprio indivíduo. Ela avalia o nível de satisfação por meio de um índice de experiências positivas e frequência de experiências negativas. Essa avaliação apoia-se em expectativas, emoções, valores, pensamentos, concepções e sentimentos subjetivos. Ela representa a forma cognitiva da vida pessoal e, muitas vezes, não envolve elementos econômicos, mas o bem-estar das pessoas em relação aos aspectos positivos ou negativos de fatos importantes da vida (Diener, 1984, 2000; Diener et al., 1999; Diener \& Ryan, 2009). Em função de a avaliação ser feita pelo próprio indivíduo, torna-se um indicador subjetivo de qualidade de vida (Diener, 1984, 2000; Diener et al., 1999; Diener \& Ryan, 2009).

O referencial do BES vem sendo abordado no Brasil desde 1993 e ganhou maior evidência a partir dos anos 2000. Estudos de Albuquerque e Tróccoli (2004) validaram a escala de BES adaptada à população brasileira. Devido às múltiplas dimensões de medidas utilizadas para compreensão do BES e à amplitude de sua definição, tornou-se um indicador relevante para avaliar a saúde mental. Ao longo do tempo, o conceito tornou-se relativamente estável e assumiu relevância para a área da psicologia da saúde, por suas influências cumulativas sobre a longevidade e a saúde em geral (Diener \& Chan, 2011). 


\section{Satisfação Geral com a Vida}

O envolvimento das duas categorias, cognitiva e emocional, propiciou a avaliação da vida pela própria pessoa, sem a necessidade de avaliação externa da qualidade de vida. Esta avaliação, embora subjetiva, identifica a satisfação cotidiana, independente de fatores externos - políticos, sociais, de triunfo, de saúde e outras variáveis - que possam medir, de forma objetiva, a qualidade de vida e o quanto a pessoa sente-se satisfeita e feliz (Giacomoni, 2004; Nunes, Hutz, \& Giacomoni, 2009). Reconhecer a satisfação com a vida como aspecto cognitivo entre as dimensões do BES proporcionou aos pesquisadores de psicologia desenvolver teorias mais consistentes, proceder investigações, utilizar medidas específicas e avaliar as relações entre o componente cognitivo e o emocional (Siqueira \& Padovam, 2008).

Assim, considera-se que os indivíduos avaliam suas vidas a partir de aspirações e comparações com fatos ocorridos no passado, bem como utilizam outras pessoas como parâmetros e modelos ideais de satisfação (Michalos, 1985; Cachioni et al., 2017). Isto pode levar a certo grau de discrepância entre a condição atual e o padrão comparado, pela possibilidade de envolver uma comparação superior, o que resultará na diminuição da satisfação. No entanto, se a comparação for direcionada a uma situação inferior, levará ao aumento na satisfação (Giacomoni, 2004).

Esta avaliação ocorre sob três perspectivas distintas: (i) satisfação com a vida em geral; (ii) satisfação em apenas um núcleo, como trabalho, casamento, saúde, entre outros; e (iii) satisfação em determinado aspecto dentro de um núcleo, como o reconhecimento de trabalho pelo departamento (Glatzer, 1987; Ryff, 2013). A satisfação é subjetiva e não dependente de situações momentâneas, por isso, é menos sensível às súbitas mudanças de humor, ao contrário do que ocorre com a felicidade (Vermunt, Spaans, \& Zorge, 1989). A satisfação também sofre influências em aspectos mais amplos de vida, por exemplo, preocupações socioeconômicas (Mckennell, 1978).

O conceito ainda pode ser considerado subjetivo na avaliação da qualidade de vida, juntamente com o bem-estar e a felicidade. Entende-se que aspectos objetivos, como ambiente físico, moradia e saúde, são quantificáveis e demonstram melhor a qualidade de vida de uma pessoa. Isto não ocorre no aspecto subjetivo, devido à dificuldade em mensurar as diferenças culturais na percepção do padrão de vida (Siqueira \& Padovam, 2008). No entanto, uma adequada adaptação está relacionada com o equilíbrio entre o afeto positivo e o afeto negativo na vida dos sujeitos (English \& Carstensen, 2015).

\section{Afetos Positivos e Afetos Negativos}

Diferentemente do componente cognitivo, o componente emocional, representado pelos afetos, é mais sensível às preocupações de vida imediata da pessoa (Mckennell, 1978). Os afetos são categorizados como a terceira dimensão na avaliação do bem-estar e demonstram a preponderância entre as circunstâncias vividas pelo indivíduo (Bradburn, 1969). Já Giacomoni (2004) busca enfatizá-los por meio de apontamentos das experiências e emoções positivas e negativas, que ocorrem em determinados períodos da vida, e o quanto o indivíduo encontra-se predisposto a elas. 
A percepção de infelicidade ou felicidade está relacionada à frequência dos afetos vivenciados (Lyubomirsky, King, \& Diener, 2005). A personalidade é uma das estruturas que podem influenciar a pessoa a sentir-se feliz ou não (Brebner, Donaldson, Kirby, \& Ward, 1995). Estudos realizados na década de 1960 mostraram que os afetos são variáveis independentes; mesmo que a relação entre os componentes seja, muitas vezes, controversa, as variáveis permanecem independentes em níveis proporcionais (Diener, 1984).

Pode-se dizer, de maneira ampla, que pessoas satisfeitas com a vida possuem um elevado nível de bem-estar. Isto ocorre devido à relativa ausência de afeto negativo e à maior presença de afeto positivo. $O$ fato de o afeto positivo se sobressair ao afeto negativo é denominado balança hedônica, o que sugere três importantes aspectos do BES que merecem ser destacados: (i) a subjetividade, em que o bem-estar compõe a experiência do indivíduo; (ii) a compreensão, em que o bem-estar vai além da ausência de fatores negativos; e (iii) o bem-estar inclui uma medida global ao invés de somente uma medida limitada de um aspecto da vida (Diener, 1984).

Os traços de personalidade e os níveis de afetos estão diretamente associados, sendo o modelo dos cinco grandes fatores associados ao afeto. Mccrae e John (1992) abordam quesitos gerais da personalidade como: (i) neuroticismo; (ii) realização; (iii) extroversão; (iv) abertura; e (v) socialização. Esse modelo esclarece aproximadamente uma variância de $24 \%$ de afeto positivo e $30 \%$ de afeto negativo, sendo que o neuroticismo e a extroversão são, de forma geral, os fatores da personalidade com maior relevância no prognóstico de afeto (Steel, Schmidt, \& Schultz, 2008). Diferentemente do afeto positivo, sujeitos que apresentam alto nível de afeto negativo vivenciam repetidamente momentos de intenso desprazer, sendo percebidos como preocupados, tristes e desanimados (Watson, 2005). Os afetos negativos são responsáveis pela suposta constatação de incapacidade e inadequação social tida pelo indivíduo (Lyubomirsky et al., 2005).

Sentimentos desagradáveis, como distração e falta de engajamento, ocorrem por períodos transitórios, acompanhados por emoções não prazerosas e aflitivas: agitação, ansiedade, aborrecimento, pessimismo, depressão, entre outras. Normalmente, o alto nível de afeto negativo também está relacionado à ruminação e pode potencializar o desenvolvimento de psicopatologias (Miles, Macleod, \& Pote, 2004; Zanon \& Hutz, 2010). Evidências experimentais confirmaram que as pessoas necessitam não apenas estabelecer vínculos ativos em sociedade, mas também mantê-los. Caso isso não ocorra, o indivíduo mostra maior tendência a apresentar níveis de sofrimento (Diener \& Seligman, 2004). Um estudo verificou que a participação em grupos de amigos, de trabalho ou de apoio, apresenta fatores favoráveis para o desenvolvimento de afetos positivos, fazendo com que estes se sobressaiam aos afetos negativos, o que proporciona o aumento de BES (Diener \& Seligman, 2004).

Nesse sentido, o envolvimento com o trabalho está diretamente conectado às dimensões subjetivas do indivíduo e às atividades exercidas por ele no meio laboral, sendo relacionado ao recurso empreendido - material, social ou pessoal - a fim de obter êxito na execução da atividade (Siqueira, Orengo, \& Peiró, 2014). O envolvimento com o trabalho como um dos principais 
vínculos afetivos entre a atividade profissional e o indivíduo está relacionado com três características pessoais referentes a esse envolvimento: crença em controlar os fatos da vida; autovisão positiva; crescimento e satisfação pessoal (Siqueira \& Gomide, 2004).

No contexto organizacional, tal envolvimento estabelece uma base competitiva fundamental no mundo dos negócios e possibilita ativar a motivação dos empregados (Brown, 1996). Ao se envolver com o trabalho, os vínculos afetivos que o indivíduo estabelece com a organização são fortalecidos - satisfação com contextos específicos do trabalho, socialização, empenho, oportunidade de crescimento, remuneração e liderança -, bem como sua satisfação geral com o trabalho e seu comprometimento efetivo (Kühnel, Sonnentag, \& Westman, 2009). Tal envolvimento torna-se relativamente estável dada às atitudes exercidas pelo trabalhador, por ele julgar necessário corresponder às demandas de trabalho da organização e atendê-las.

Por todo exposto, o presente estudo adota a perspectiva de que o BES é formado pelas expectativas, valores, emoções, pensamentos, concepções e sentimentos subjetivos que o indivíduo utiliza para avaliar a própria vida, sendo a satisfação geral com a vida um importante construto a ser analisado devido às circunstâncias de comparação do indivíduo com a própria vida em seu meio social, cultural e histórico. Essa variável é pesquisada na perspectiva de afetos positivos, como gratidão, felicidade, otimismo, esperança, virtude e resiliência, além dos afetos negativos, como ansiedade, agitação, aborrecimento, pessimismo e depressão, os quais têm um impacto na satisfação geral com a vida.

\section{- Procedimentos Metodológicos}

A presente pesquisa é de abordagem qualitativa exploratória e foi realizada com imigrantes senegaleses vinculados ao quadro de empregados de um frigorífico localizado em uma cidade de pequeno porte no norte do estado do Rio Grande do Sul. Essa empresa foi escolhida por ela se mostrar preocupada com a qualidade de vida e com o bemestar de seus empregados, assim como pela possibilidade de acesso aos empregados.

Foram entrevistados 20 imigrantes senegaleses, residentes na cidade em que o frigorífico está instalado, do sexo masculino e atuantes na linha de produção. Alguns eram casados no Senegal e possuíam filhos, porém deixaram seus familiares e vieram sozinhos para o Brasil. Os que vieram solteiros ainda permaneciam nessa condição e todos professavam a religião muçulmana. O grau de escolaridade dos entrevistados variou de ensino fundamental a superior incompleto, enquanto a idade entre 18 a 50 anos e o tempo de permanência no Brasil foi de oito meses a seis anos.

Contou-se com a participação de um intermediador para auxiliar na condução dos grupos focais, quando os imigrantes se comunicavam em wolof, dialeto por eles utilizado. Ao intermediador cabia fazer a tradução para o português. A escolha do intermediador ocorreu por ele já ter participado 
de pesquisas anteriores com imigrantes senegaleses, pela fluência em português e disponibilidade de tempo. Essa disponibilidade era importante, tendo em vista que seria preciso tanto fazer um treinamento antes das execuções dos grupos focais, como acompanhar as pesquisadoras em parte da coleta de dados. Considerou-se importante que o intermediador não tivesse vínculos com a empresa, para que não exercesse nenhum tipo de influência nas discussões ocorridas nos grupos focais.

O intermediador recebeu instruções de como proceder durante a execução dos grupos e também sobre os conceitos que seriam trabalhados com os participantes, pois sua compreensão do que seria perguntado daria um forte indício de que os imigrantes também compreenderiam. Nesta ocasião, houve a necessidade de sair da teoria e exemplificar de forma prática, pois o intermediador disse não compreender o que se queria saber com as perguntas formuladas, devido às palavras serem muito difíceis. Após a exemplificação prática dos conceitos, conseguiu-se a compreensão do intermediador. O treinamento foi realizado em dois momentos anteriores aos grupos focais, os quais duraram aproximadamente seis horas ao total.

O intermediador disponibilizou-se a acompanhar a pesquisadora até a empresa. Ele conseguiu explicar, em wolof, para um grande número de imigrantes, o objetivo da pesquisa, pois, naquele momento, ocorria a troca de turno de trabalho. Muitos demonstraram interesse em participar do estudo, porém disseram que só o fariam devido à confiança que depositavam no intermediador. Destes, foram escolhidos aqueles que tinham melhor compreensão da língua portuguesa e pela disponibilidade em fazer parte do estudo.

A coleta de dados foi realizada em duas fases, no período de 10 a 20 de dezembro de 2016, conforme a disponibilidade do intermediador e dos participantes. A primeira fase teve início com o grupo focal realizado em uma sala no edifício residencial na qual uma das autoras mora, sendo considerado um espaço neutro para evitar que os imigrantes tivessem receio de expor seus sentimentos e sofrer represálias na empresa. Foram realizados quatro grupos focais, de aproximadamente duas horas cada, sendo que as conversas foram gravadas, mediante autorização, e depois transcritas.

O primeiro grupo foi utilizado como teste do procedimento, com o intuito de verificar se os temas derivados das escalas iriam corresponder ao interesse da pesquisa em descrever o BES dos imigrantes. O objetivo dessa etapa era obter a correta compreensão das verbalizações de cada imigrante no grupo focal e avaliar a conduta do intermediador. Este grupo também foi adotado para a análise dos resultados, por ter correspondido às expectativas do teste de procedimento.

Depois da leitura dos conceitos e das questões e após tradução destes conteúdos para wolof, os participantes começavam a responder. Alguns conseguiam se comunicar em português, outros respondiam em wolof, caso em que o intermediador fazia a tradução do dialeto para o português. Para resguardar a identidade dos participantes, eles foram nomeados com um código, ao final de suas verbalizações (Quadro 2). 
Quadro 2. Código de identificação dos participantes por grupos

\begin{tabular}{cccc}
\hline Grupo Focal 1 & Grupo Focal 2 & Grupo Focal 3 & Grupo Focal 4 \\
\hline P1.G1 & P1.G2 & P1.G3 & P1.G4 \\
P2.G1 & P2.G2 & P2.G3 & P2.G4 \\
P3.G1 & P3.G2 & P3.G3 & P3.G4 \\
P4.G1 & P4.G2 & P4.G3 & P4.G4 \\
& P5.G2 & P5.G3 & P5.G4 \\
& P6.G2 & & \\
\hline
\end{tabular}

Fonte: Elaborado pelas autoras (2018).

Abordaram-se questões relacionadas ao BES dos imigrantes em relação à satisfação geral com a vida, afetos positivos e afetos negativos, com base no que foi exposto no referencial teórico. Os grupos foram executados com o intuito de detectar aspectos subjetivos. Para isso, o formato reduzido dos grupos (cinco imigrantes cada um) apresentou-se mais eficaz para execução e mediação da técnica, tendo em vista a dificuldade dos imigrantes em se comunicarem usando a língua portuguesa.

A segunda fase da pesquisa foi composta por gestores que possuíam contato direto com os senegaleses pesquisados nos grupos focais. No momento da pesquisa, a empresa apresentava dois coordenadores e dois supervisores de produção, responsáveis pelos turnos de trabalho da produção. Entretanto, a coordenadora de produção do primeiro turno não possuía experiência específica com os participantes, o que impossibilitou sua participação na pesquisa. Apenas a supervisora do primeiro turno foi considerada apta a participar da pesquisa. Quanto ao segundo turno de produção, a supervisora estava, naquela ocasião, se desligando da empresa e não demonstrou interesse em participar da pesquisa. O coordenador de produção, no entanto, possuía todos os pré-requisitos.

Houve interesse também em entrevistar o gestor de recursos humanos responsável pelo gerenciamento das casas disponibilizadas aos imigrantes pela empresa, devido à sua vasta experiência com os imigrantes participantes do estudo, porém ele se recusou a participar da pesquisa. Todos os gestores assinaram o termo de consentimento livre e esclarecido antes do início da entrevista. Assim como os participantes dos grupos focais, os gestores também receberam um código para ser colocado após suas falas. A supervisora do primeiro turno recebeu o código (E1) e o coordenador de produção recebeu o código de (E2). As entrevistas foram realizadas em uma sala separada na empresa e tiveram a duração média de 42 minutos, totalizando 12 páginas de transcrição das duas entrevistas.

A pesquisa apresentou dois vieses. Um ocorreu nas transcrições das falas dos imigrantes que não possuíam fluência em português e outro por eles se expressarem em voz baixa, houve dificuldade em identificar, com clareza, seu tom de voz, fato que gerou dúvidas na identificação de suas verbalizações no decorrer do grupo focal.

Para a análise dos resultados adotou-se a técnica análise de conteúdo, por constituir um conjunto de técnicas a serem utilizadas na análise dos 
dados qualitativos, que permitem a apreciação das comunicações e fornecem informações suplementares (Bardin, 2011). Utilizou-se a priori uma categoria principal, com três subcategorias, as quais foram os temas norteadores das questões abordadas nos grupos focais e estavam fundamentadas na revisão da literatura e nos objetivos da pesquisa (Bardin, 2011). Essas categorias serviram como base para alocar os conteúdos identificados nas verbalizações, que ocorreram no grupo focal e em recorrência quando houve necessidade, bem como para os resultados da entrevista semiestruturada.

Para identificar as falas correspondentes às categorias e subcategorias foi necessário criar itens temáticos para alocar as verbalizações dentro de cada contexto (Quadro 3). Somente após a identificação dos itens temáticos foi possível alocar as verbalizações correspondentes a cada subcategoria. Quadro 3. Identificação de itens temáticos dentro de cada subcategoria

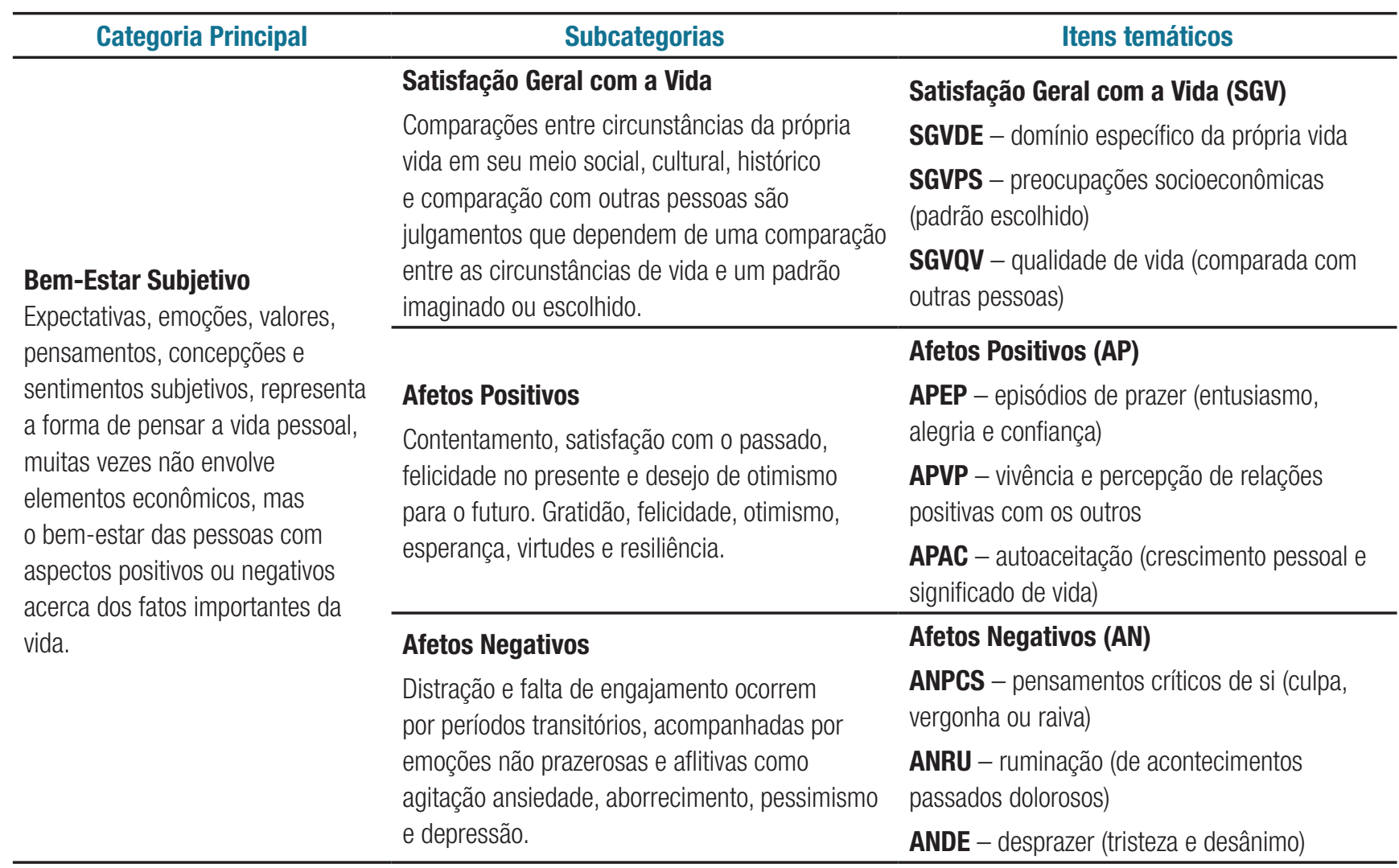

Fonte: Elaborado pelas autoras (2018).

Também foi utilizada uma triangulação de dados, que supera as limitações de um único método (Flick, 2009). A partir da participação de uma das pesquisadoras nas festividades dos imigrantes e nas visitas à empresa, foi estruturado um diário de campo. Este diário, juntamente com as entrevistas, documentos da empresa e dados de imigração disponíveis na internet foram utilizados na triangulação dos dados. Essa triangulação permitiu que os dados coletados fossem melhor compreendidos frente ao contexto da imigração dos senegaleses. 


\section{Análise e Discussão dos Resultados}

A análise dos resultados está estruturada em três categorias que permitem compreender o BES dos imigrantes senegalês pesquisados: satisfação geral com a vida, afetos positivos e afetos negativos.

\section{Satisfação geral com a vida}

A satisfação geral com vida buscou analisar quais aspectos influenciam direta e indiretamente a sensação de satisfação ou insatisfação com a vida desses imigrantes. O principal conteúdo identificado, em todos os grupos focais, foi o fator econômico, no qual relatam que "meu bem-estar é o trabalho, muito trabalho, é guardar dinheiro no banco e não gastar, é pensar no futuro" (P1.G3.SGVDE). E ainda complementam que "o bem-estar é ganhar dinheiro, ganhar dinheiro, fico feliz por isso" (P3.G1.SGVDE).

Nesse contexto, foram as dificuldades econômicas e sociais que impulsionaram os africanos a migrar em busca de oportunidades de trabalho (Zamberlam et al., 2014). Este cenário justifica-se devido à fraca economia e a pouca oportunidade de trabalho oferecida no país de origem, resultante da presença excessiva de população jovem ali residente. Tal fato decorre da guerra pela colonização do Senegal e contribui para que, muitas vezes, a imigração seja a única alternativa para os jovens senegaleses (Espeiorin, 2014).

Já as percepções dos gestores foram identificadas com o mesmo domínio específico relatado pelos imigrantes senegaleses, sendo o fator econômico o aspecto mais importante que contribui para a satisfação dos sujeitos estudados. Neste item, E1 (SGVDE) relata que os imigrantes "precisam de dinheiro, vieram por dinheiro. Vejo que eles ficam insatisfeitos no momento em que mexe no bolso deles, quando acontece um problema com dinheiro eles ficam bem alterados".

Nas verbalizações sobre preocupações socioeconômicas, o item citado com mais frequência foi a ajuda à família. Isto leva alguns desses senegaleses a terem que trabalhar em mais de um lugar para conseguirem seu sustento no Brasil e ainda mandar dinheiro para seus familiares que ficaram na África (Dill et al., 2015). Tal contexto é apontado por P3 (G2.SGVPS): "eu vim aqui para buscar trabalho e ganhar muito dinheiro para ajudar minha família que vive no Senegal. É muito importante para mim ter dinheiro para construir a casa. Ganhar dinheiro, ajudar a família". E ainda ressaltam que "quando eu cheguei aqui, eu consegui trabalho, eu ajudei minha família" (P4.G3.SGVPS).

Os gestores da empresa contribuem para essa percepção, pois a ajuda para a família é o que mais influencia na preocupação socioeconômica dos senegaleses, havendo influência direta em seu sentimento de satisfação com a vida, conforme o relato do E2 (SGVPS):

\footnotetext{
Família em primeiro lugar é o que a gente vê que mexe mesmo com eles. Tocar na família para conversar, você já ganha eles. Eles dizem: 'mando lá $60 \%$ para a família'. Eles ficam aqui e comem só o necessário. A porcentagem que fala: 'estou bem aqui' é mínima. Eles vivem com o mínimo aqui, o resto é tudo para a família.
} 
Esses apontamentos corroboram com a perspectiva de que o trabalho tem um papel importante para o ser humano por relacionar aspectos tanto materiais quanto subjetivos ao cotidiano das pessoas, além de proporcionar a busca pela subsistência, possibilitar uma vida melhor e um futuro próspero (Semeraro, 2013). Nesse sentido, as preocupações socioeconômicas são influenciadoras na satisfação da vida dos indivíduos (Mckennell, 1978).

Em relação à qualidade de vida, os imigrantes fizeram um comparativo entre sua situação atual no Brasil e a vivenciada anteriormente no Senegal. Assim, o item que apareceu como predominantes foram os serviços ofertados pelo governo do Brasil e, principalmente, o acesso gratuito à saúde. Para os entrevistados, "no Senegal, quando você for tratar a saúde você vai ter que pagar. No Brasil, ninguém paga e isso é bom para mim" (P2.G4.SGVQV). Tal percepção também foi relatada por outros participantes, como se pode perceber no depoimento do P5 (G4.SGVQV): "quando você trabalha e fica doente, vai ao hospital e não precisa pagar nada. Se você ficar doente e precisar de um atestado, você descansa e não perde nada do salário". Essas falas mostram que a qualidade de vida está relacionada além de uma questão financeira, mas à estrutura médica e poder cuidar da saúde quando necessário.

Isto serve de contraponto aos resultados do estudo de Nunes et al. (2009) que mostram esta avaliação como subjetiva e identifica a satisfação cotidiana, independente de fatores externos, políticos, sociais, de triunfo, de saúde e de outras variáveis que possam medir, de forma objetiva, a qualidade de vida e o quanto a pessoa sente-se satisfeita e feliz. Nesse sentido, a análise da percepção dos imigrantes vai ao encontro do conceito explicitado por Shin e Johnson (1978), no qual as comparações entre circunstâncias da própria vida em seu meio social, cultural, histórico e entre outras pessoas são julgamentos que dependem de uma comparação entre as circunstâncias de vida e um padrão imaginado ou escolhido, ou seja, remete também a uma comparação com o meio social, cultural e histórico.

Quanto à percepção dos gestores, o E1 não se manifestou, enquanto que o E2 comentou que não conseguiu identificar tal satisfação entre os imigrantes. Isto pode ser justificado devido a certo grau de discrepância entre a condição atual e o padrão comparado, pois se envolver em uma comparação superior resultaria na diminuição da satisfação (Giacomoni, 2004). No entanto, se a comparação fosse direcionada a uma situação inferior, levaria ao aumento da satisfação, como pode se perceber no relato do P3 (G2.SGVQV): "se eu estou doente, eu vou lá no hospital, tudo grátis, não tem problema. Diferente de lá no Senegal”.

\section{Afetos Positivos}

A análise das entrevistas permite perceber que a paz que os imigrantes encontram no Brasil, aliada à liberdade de exercer a religião muçulmana, influencia o sentimento de prazer dos imigrantes, pois "não tem que incomodar muito, nem a polícia, nem ninguém, aqui temos liberdade, para fazer tudo isso e [praticar] nossa religião" (P4.G1.APEP). Mencionam ainda que "todo dia eu faço oração perto do meu guia espiritual. Aqui, eu não tenho problema, eu trabalho, ganho meu dinheiro, volto lá na minha casa e durmo, eu estou bem" (P1.G1.APEP). 
Este fato pode ser justificado por se tratar de um estado de espírito e não de uma situação momentânea. Fraga (2006) expõe que os africanos buscavam constituir redes familiares e, por meio delas, sentiam-se mais seguros e protegidos. A afirmação de Fraga (2006) se reflete na seguinte verbalização "quando estamos reunidos nos domingo para fazer oração, só os senegaleses e falando wolof, ele fica feliz, está bem" (P3.G1.APEP). Tais encontros religiosos permitem aos senegaleses sentirem-se em uma atmosfera familiar, mesmo estando em outro país. A participação em grupos de amigos, de trabalho ou de apoio apresenta fatores favoráveis para o desenvolvimento de afetos positivos, pois faz com que estes se sobressaiam aos afetos negativos e proporcionem o aumento de BES (Diener et al.,1999).

Assim, a religião é percebida como um importante papel nos afetos positivos dos senegaleses. A E1 (APEP) relata a sua percepção: "eles são extremamente religiosos de orações e em seguir a religião, eles cuidam muito disso. Desde a parte de comida, no que falar, na parte do que fazer, de vestir, são bem tradicionalistas. Eles se reúnem e fazem as orações. A gente vê a positividade, a alegria deles".

Ainda na subcategoria do afeto positivo observa-se, no item temático vivências e percepções, que um dos fatores que exerce influência na satisfação geral com a vida dos imigrantes senegaleses são as vivências e as experiências, tanto com amigos brasileiros quanto os senegaleses. Esse aspecto é observado quando "a gente vem no Brasil e não tem problema, tem muita gente boa para o senegalês, não tem racismo" (P3.G2.APVP) e "tem bastante amigos para conversar, que fica feliz quando está com eles" (P5.G2.APVP). Esses achados vão ao encontro dos apontamentos de Bradburn (1969), ao categorizar os afetos como uma dimensão para avaliar o bem-estar. Além disso, corroboram o modelo multidimensional de bem-estar de Ryff e Keyes (1995), ao contemplar as seis dimensões (autoaceitação, crescimento pessoal, objetivo e significado de vida, relação positiva com outros, domínio de ambiente e autonomia) do modelo.

As vivências positivas são identificadas por ambos os gestores como influenciadoras do BES dos imigrantes senegaleses, conforme relata a E1 (APVP):

São bem felizes entre eles. São muito espertos, cuidam muito uns dos outros. Eles são muito unidos, muito, muito unidos, são mais na deles do que misturados com brasileiros. Se protegem muito, o que acontece com um, tu pode estar preparado que vai ser para todos. Eles abrem bastante a vida deles e perguntam da gente. Conversar isso com eles favorece bastante para nós. Eles estão lá cantando e trabalhando, às vezes, ficam o dia inteiro cantando. Se sentirem que tu gosta deles, eles te tratam totalmente diferente.

Ainda, nesse mesmo sentido, o E2 (APVP) complementa:

Pelo tratamento de brasileiros, de senegaleses, acho que vivem bem, tranquilo, tem uma boa relação. Eles são bem unidos, se acontece alguma coisa com um amigo, por exemplo, pode ser uma suspensão que um supervisor dá, eles já sentem isso, aí já fica revoltado com o supervisor. Se você tratar eles bem, der atenção, eles te dão um rendimento maior. A gente peca ainda nisso. 
A autoaceitação como item temático apresenta a satisfação que os imigrantes senegaleses possuem em relatar suas experiências de estudo, quer com o aprendizado de outros idiomas, em seu país de origem, quer com a aquisição gradativa de conhecimento do português que eles estão conseguindo. Eles se demonstram orgulhosos por terem conhecimento e experiências no Senegal, com profissões mais gratificantes do que aquelas que exercem no Brasil. Nesse sentido, o P4 (G3.APAC) relata que "era estudante em Senegal [e estudava] língua espanhola e inglesa" (P4.G3.APAC), enquanto que o P1 (G3.APAC) menciona que "era estudante na Universidade do Senegal. Eu fazia árabe como língua, economia, marketing e contabilidade".

Os relatos dos entrevistados também evidenciam sua deficiência na comunicação em português e sua inserção nas cidades brasileiras, no trabalho e na sociedade. Tal contexto pode ser percebido na fala do P2 (G1.APAC): "no bairro que moro, têm amigos que ajudam a falar bem português". Os depoimentos mostram que eles se orgulham ao transformar aspectos difíceis de suas vivências em experiências positivas e de valorização de si mesmo (Costa \& Gelmino, 2012).

Conforme observado na seleção dos participantes, bem como nos grupos focais, percebeu-se que a maioria dos imigrantes ainda não consegue se comunicar fluentemente em português. No entanto, enquanto a E1 (APAC) observa que "eles entendem muito bem porque faz tempo que a gente não contrata nenhum e todos eles entendem muito bem", o E2 (APAC) relata que "hoje, há uma porcentagem bem pequena que sabem o português", corroborando com a percepção dos imigrantes entrevistados e com a realidade do campo explorado durante a pesquisa.

\section{Afetos Negativos}

Neste item temático, a sensação de arrependimento por terem saído do Senegal sem conhecer a realidade na qual iriam se inserir no Brasil foi frequentemente apontado pelos entrevistados. O E2 (ANPCS) relata a desmotivação dos imigrantes, pois a realidade "não é o que eles pensavam que iam encontrar aqui. Isso foi bastante desmotivante para eles". Muitos dos entrevistados imigrantes pensavam que iriam receber o pagamento do salário em dólares e, portanto, deixaram seus trabalhos, seus familiares e fizeram um investimento financeiro alto para virem ao Brasil, conforme relata o P2 (G2.ANPCS):

Tem muita gente que tinha trabalho ganhando mais e deixou o Senegal para vir para cá porque eles não sabiam de nada. Quando você vem aqui no Brasil, todo Senegal sabe que você está rico, tem mais dinheiro. Só que não é assim. Quando eu estava no Senegal gastava muito dinheiro, eu ganhava mais, mas não conseguia guardar no banco, gastava tudo. Todos os senegaleses que foram para a França e Estados Unidos, nesse momento, estão ricos.

Esses relatos mostram uma contradição nas falas dos imigrantes. Ao mesmo tempo em que eles imaginavam uma vida melhor no Brasil por terem ouvido falar de outras pessoas - e, ao chegarem ao Brasil, perceberam que não era aquilo que esperavam -, eles reproduzem o mesmo discurso 
daqueles imigrantes que estão em outros países - de que lá é melhor -, sem conhecer e ter vivenciado a realidade do país. Nesse sentido, o afeto negativo não está relacionado ao país em questão, mas ao processo de imigração e aos sujeitos envolvidos.

Os sujeitos que apresentam alto nível de afeto negativo vivenciam repetidamente momentos de intenso desprazer e são percebidos como pessoas preocupadas, tristes e desanimadas (Watson, 2005). Normalmente, o alto nível de afeto negativo também está relacionado à ruminação e pode potencializar o desenvolvimento de psicopatologias (Miles, Macleod, \& Pote, 2004).

No item temático ruminação, identifica-se que os afetos negativos que mais influenciam o BES dos imigrantes são a saudade da família e algumas situações de decepção vivenciadas no decorrer da vida. Esses fatos ficam evidentes quando comentam que sentem "saudade da mãe, não dá para ir visitar sem documento" (P1.G1.ANRU), bem como "quando ele está sozinho, está pensando quando vai conseguir voltar, não tem paz" (P2. G3.ANRU). Esses relatos corroboram os apontamentos de que a percepção de infelicidade ou felicidade está relacionada com a frequência de afetos vivenciados, os quais, quando de caráter negativos, são responsáveis pela suposta constatação de incapacidade e inadequação social tida pelo indivíduo (Lyubomirsky et al., 2005).

Pela percepção dos gestores, identifica-se o quanto a saudade da família exerce influência nos afetos negativos dos imigrantes. A realidade vivenciada pelos senegaleses no Brasil recebe interferência da política imigratória brasileira, pois, devido à sua desatualização, impede os imigrantes de irem visitar seus familiares e retornarem para o Brasil para continuar a trabalhar.

Ao questionar sobre o desprazer, os imigrantes relatam questões relacionadas ao racismo e a falta de respeito com que, muitas vezes, são tratados pelos gestores. Conforme menciona P3 (G4.ANDE), "a população, não é todo mundo igual, tem uns que nos aceitaram, outros têm preconceito". Já o P1 (G4.ANDE) observa que o "supervisor sempre fala feio para o negro, ele vai mandar embora o senegalês". Nesse contexto, Fernandes e Castro (2014) explicam que a inclusão social nem sempre ocorre como o esperado, pois ainda há muito preconceito. Os imigrantes africanos sofrem preconceito especialmente por sua cor de pele. Com frequência, eles não são bem vistos por supostamente tirarem vagas de emprego de brasileiros (Espeiorin, 2014).

Segundo a percepção dos gestores, os imigrantes, muitas vezes, não conseguem entender as políticas da empresa, por isso, consideram a cobrança do cumprimento das regras como um ato racista porque "eles vão muito pela pessoa, se a pessoa não vai muito com a cara deles, eles não gostam. Eles me falam, o chefe lá não gosta de mim" (E2.ANDE). Isso pode ser explicado pelo estudo de Rabello, Lague, Nogueira e Macke (2016) que ao investigarem a percepção da cultura organizacional entre expatriados e imigrantes, observaram que quanto maior o tempo de vínculo com a organização, mais ampla torna-se a percepção de seus valores e de suas práticas, bem como quanto mais elevado o cargo ocupado pelo indivíduo, mais ampla torna-se sua percepção. 


\section{Considerações Finais}

Ao chegarem ao Brasil, imigrantes senegaleses se deparam com a desatualização da política imigratória, a falta de adequação de políticas públicas, a violação de direitos humanos e a percepção negativa da mobilidade humana pela opinião pública (Zamberlam et al., 2014). Além do aspecto social, ao se inserirem no mercado de trabalho, também enfrentam dificuldades de adaptação ao meio organizacional. Esses contextos podem se irradiar para a vida pessoal, familiar, social e influenciar os níveis de bem-estar, saúde física e mental do indivíduo (Siqueira \& Gomide, 2004). Isso porque as condições de trabalho que são expostos incluem aspectos afetivos, como emoção e cognição, mediante às percepções que os imigrantes têm cotidianamente.

Nesse contexto, o presente estudo visou analisar o BES de imigrantes senegaleses no norte do Rio Grande do Sul. Consideraram-se suas percepções no aspecto pessoal de suas vidas e ao meio laboral. Foram evidenciados aspectos da satisfação geral com a vida, entre eles, o dinheiro, a ajuda à família, os serviços oferecidos pelo governo e, principalmente, a saúde. Quanto aos fatores de afetos positivos, destacam-se a prática da religião, a paz que eles encontram no país, a amizade com os brasileiros e com outros senegaleses, a oportunidade de aprender outro idioma e as vivências pessoais e profissionais. Também encontraram-se fatores de afetos negativos, entre eles, a saudade dos familiares que ficaram no Senegal, algumas situações de decepção no decorrer da vida, o racismo, alguns atos de desrespeito e expectativas frustradas, pois a realidade encontrada não correspondeu ao que tinham imaginado.

Verificou-se, portanto, que o BES de imigrantes senegaleses é influenciado por aspectos econômicos e familiares, pelo acesso à saúde, pela religião e pelo sentimento de igualdade. Embora a empresa perceba que os senegaleses não demonstram interesse em permanecer por muito tempo no quadro de empregados da empresa, os imigrantes entrevistados demonstraram interesse em permanecer por mais tempo na empresa, desde que percebam oportunidades de crescimento, sejam bem remunerados e tratados com igualdade.

Os resultados mostram a necessidade de haver um setor dentro da empresa que trabalhe com a gestão da diversidade, gerada pela inserção desses imigrantes. Além disso, é importante um gestor que entenda da cultura desses imigrantes, para que seja possível fazer os ajustes culturais necessários, podendo gerar maior entrosamento e motivação desses senegaleses. Pode-se perceber nos grupos focais que, muitas vezes, esses imigrantes não entendem às políticas e práticas da empresa, atribuindo às cobranças como atos de desigualdade. Assim, a empresa também necessita estar mais preparada para trabalhar com esses imigrantes, devido aos valores e culturas diferentes de ambos os países. Mostrou-se importante que as empresas que optem por terem imigrantes em seu quadro de empregados desenvolvam um olhar de multiculturalismo na gestão do trabalho. 
Sugere-se que, em estudos futuros, seja abordada a cultura com imigrantes senegaleses a fim de analisar como ela influencia seus comportamentos no ambiente laboral. Tal estudo poderá evidenciar os fatores que influenciam o BES e o bem-estar no trabalho de imigrantes senegaleses, mostrando uma vertente social e psicológica da realidade na qual esses imigrantes encontram-se inseridos no Brasil. Nesse mesmo sentido, sugere-se a ampliação do estudo para uma pesquisa longitudinal, tendo em vista que a literatura aponta que o tempo de permanência no país de destino afeta a percepção do estrangeiro em relação aos aspectos de BES na sua vida e no seu trabalho (Stahl \& Caligiuri, 2005; Rabello et al., 2016).

\section{Referências}

Acnur - Alto Comissariado Das Nações Unidas Para Refugiados. (2016). Dados sobre refúgio no Brasil. Recuperado em 26 julho, 2018, de http://www.acnur.org/ portugues/dados-sobre-refugio/dados-sobre-refugio-no-brasil/

Acnur - Alto Comissariado Das Nações Unidas Para Refugiados. (2015). SEDS e ACNUR promovem capacitação para atendimento social a refugiados e migrantes. Recuperado em 31 julho, 2016, de http://www.acnur.org/portugues/noticias/noticia/ seds-e-acnur-promovem-capacitacao-para-atendimento-social-a-refugiados-emigrantes/?sword_list ]=migra\%C3\%A7\%C3\%B5es\&no_cache=1

Albuquerque, A., \& Troccóli, B. (2004). Desenvolvimento de uma escala de bemestar subjetivo. Psicologia: Teoria e Pesquisa, 20(2), 153-164.

Andrews, F., \& Robinson, J. (1991). Measures of subjective wellbeing. In: Robinson, J., Shaver, P., Wrightsman, L. (Orgs.). Measures of Personality and Social Psychological Attitudes. San Diego: Academic Press, 61-67.

Bardin, L. (2011). Análise de conteúdo. São Paulo: Edições 70.

Bradburn, N. (1969). The structure of psychological well-being. Chicago: Aldine.

Brebner, J., Donaldson, J., Kirby, N., \& Ward, L. (1995). Relationships between happiness and personality. Personality and Individual Differences, 19(2), 251-258.

Brown, S. (1996). Meta-analysis and review of organizational research on job involvement. Psychological Bulletin, 120(2), 235-255.

Cachioni, M., Delfino, L., Yassuda, M., Batistoni, S., Melo, R., \& Domingues, M. (2017). Bem-estar subjetivo e psicológico de idosos participantes de uma Universidade aberta à terceira idade. Revista Brasileira de Geriatria e Gerontologia, 20(3), 340-352.

Campbell, A., Coverse, P., \& Rogers, W. (1976). The Quality of American life: perceptions, evaluations and satisfactions. New York: Russel Sage Foundations.

Costa, P., \& Gelmino, A. (2012). Haitianos em Manaus: dois anos de imigração - e agora! Travessia - Revista do Migrante, (70), 91-99.

Csikszentmihalyi, M. (1999). A descoberta do fluxo: a psicologia do envolvimento com a vida cotidiana. (P. Ribeiro, Trad.). Rio de Janeiro: Rocco.

Diener, E. (2000). Subjective well-being - The science of happiness and a proposal for a national index. American Psychologist, 55(1), 34-43. 
Diener, E. (1996). Subjective well-being in cross-cultural perspective. In: Hector G. (Ed.). Key issues in cross-cultural psychology: selected papers from the Twelfth International Congress of the International Association for Cross-Cultural Psychology. San Diego: Academic Press.

Diener, E. (1984). Subjective wellbeing. Psychological Bulletin, 95(3), 542-575.

Diener, E., \& Diener, C. (1996). Most people are happy. Psychological Science, 7(3), 181-185.

Diener, E., \& Seligman, M. (2004). Beyond money: toward an economy of well-being. Psychological. Science in the Public Interest, 5(1), 1-31.

Diener, E., Suh, E., Lucas, R., \& Smith, H. (1999). Subjective wellbeing: Three decades of progress. Psychological Bulletin, 125(2), 276-302.

Diener, E., \& Chan M. (2011). Happy people live longer: subjective well-being contributes to health and longevity. Appl Psychol Health Well Being, 3(1), 1-43.

Diener, E., \& Ryan, K. (2009). Subjective well-being: a general overview. South African Journal of Psychology, 39(4), 391- 406.

Dill, J., Anese, V., Severo, E., \& Costa, C. (2015, novembro). Mercado de trabalho e imigração: análise da inclusão de haitianos e senegaleses em uma empresa alimentícia no Norte do Rio Grande do Sul. Anais do XXII Simpósio de Engenharia de Produção (SIMPEP), Bauru, SP, Brasil, 22.

English, T., \& Carstensen L. (2015). Socioemotional selectivity theory. In: A. Pachana Encyclopedia of Geropsychology. Singapore: Springer Singapore.

Espeiorin, V. (2014). A nova cara do imigrante. Revista UCS, 2(11).

Fernandes, D., \& Castro, M. (2014). Estudos sobre a migração haitiana ao Brasil e diálogo bilateral. Relatório Final. Recuperado em 27 fevereiro, 2018, de http://obs. org.br/cooperacao/download/34_7a099729afe2d4aaf109503e6daf3908

Flick, U. (2009). Introdução à pesquisa qualitativa (3ed). Porto Alegre: Artmed.

Fraga, W. (2006). Uma história do negro no Brasil. Salvador: Fundação Palmares.

G1. (2015). Entenda a situação de países de onde saem milhares de imigrantes à Europa. Recuperado em 28 agosto, 2018, de http://g1.globo.com/mundo/ noticia/2015/08/entenda-situacao-de-paises-de-onde-saem-milhares-deimigrantes-europa.html

Galinha, I., \& Ribeiro, J. (2005). História e evolução do conceito de bem-estar subjetivo. Psicologia Saúde \& Doenças, 6(2), 203-214.

George, L. (1981). Subjective Well Being. Conceptual and Methodological Issues. Annual Review of Gerontology and Geriatrics, 2, 345-382.

Giacomoni, C. (2004). Bem-estar subjetivo: em busca da qualidade de vida. Temas em Psicologia, 12(1), 1401-1410.

Glatzer, W. (1987). Subjective Well-being: components of well-being. Social Indicators Research, 19, 25-38.

Horley, J. (1984). Life Satisfaction, Happiness and Morale: Two problems with the use of Subjective Well-being indicators. The Gerontologist, 24(2), 124-127. 
IBGE - Instituto Brasileiro de Geografia e Estatística. (2010). Publicação aborda aspectos teóricos e analisa deslocamentos populacionais no Brasil. Recuperado em 25 de fevereiro, 2019, de https://censo2010.ibge.gov.br/noticias-censo.html? busca $=1 \& i d=1$ \&idnoticia $=1928 \& t=$ publicacao-aborda-aspectos-teoricos-analisadeslocamentos-populacionais-brasil\&view=noticia

Kühnel, J., Sonnentag, S., \& Westman, M. (2009). Does work engagement increase after a short respite? The role of job involvement as a double-edged sword. Journal of Occupational and Organizational Psychology, 82(3), 575-594.

Lawrence, R., \& Liang, J. (1988). Structural integration of the affect balance scale and the life satisfaction index A: race, sex, and age differences. Psychology and Aging, 3(4), 375-384.

Lyubomirsky, S., King, L., \& Diener, E. (2005). The benefits of frequent positive affect: does happiness lead to success? Psychological Bulletin, 131(6), 803-855.

Mccrae, R., \& John, O. (1992). An introduction to the five-factor model and its applications. Journal of Personality, 60(2), 175-215.

Mckennell, A. (1978). Cognition and affect in perception of well-being. Social Indicators Research, 5(1-4), 389-426.

Michalos, A. (1985). Multiple Discrepancies Theory (MDT). Social Indicators Research, 16(4), 347-413.

Miles, H., Macleod, A., \& Pote, H. (2004). Retrospective and prospective cognitions in adolescents: anxiety, depression, and positive and negative effect. Journal of Adolescesse, 27(6), 691-701.

Nunes, C., Hutz, C., \& Giacomoni, C. (2009). Associação entre bem estar subjetivo e personalidade no modelo dos cinco grandes fatores. Avaliação Psicológica, 8(1), 99-108.

O'Donnell, M. (1986). Definition of Health Promotion. American Journal of Health Promotion, 1(1), 4-5.

Rabello, G., Lague, J., Nogueira, J., \& Macke, J. (2016, novembro). Cultura organizacional: percepção das práticas e valores organizacionais de expatriados e Imigrantes em organizações do sul do Brasil. Anais do II Hopead - Horizontes de Pesquisa em Administração, Passo Fundo, RS, Brasil, 2.

Ryff, c. (2013). Psychological well-being revisited: Advances in the science and practice of eudaimonia. Psychother Psychosom, 83(1), 10-28.

Ryff, C., \& Keyes, C. (1995). The structure of psychological well-being revisited. Journal of Personality and Social Psychology, 4(69), 719-727.

Saraceno, B. (1995). Mental health promotion and psychiatric care: a common final path? In: D. Trent, \& C. Reed. (Orgs.). Promotion on Mental Health (4ed). Aldershot: Avebury.

Schrover, M. (2009). History of international migration. Recuperado em 13 março, 2016, de http://www.let.leidenuniv.nl/history/migration/

Seligman, M., \& Csikszentmihalyi, M. (2000). Positive psychology: an introduction. American Psychologist, 55(1), 5-14.

Semeraro, G. (2013). A concepção de trabalho na filosofia de Hegel e de Marx. Educação e Filosofia, 27(53), 87-104. 
Shin, D., \& Johnson, D. (1978). Avowed happiness as an overall assessment of the quality of life. Social Indicators Research, 5(1), 475-492.

Siqueira, M., \& Gomide, S., Jr. (2004). Vínculo do indivíduo com o trabalho e com a organização. In: J. C. Zanelli (Org.). Psicologia organizações e trabalho no Brasil. Porto Alegre: Artmed.

Siqueira, M., Orengo, V., \& Peiró, J. (2014). Bem-estar no trabalho. In: Siqueira, M. (Org.). Novas medidas do comportamento organizacional: ferramentas de diagnóstico e de gestão. Porto Alegre: Artmed.

Siqueira, M., \& Padovam, V. (2008). Bases teóricas de bem-estar subjetivo, bem-estar psicológico e bem-estar no trabalho. Psicologia: Teoria e Pesquisa, 24(2), 201-209.

Snyder, C., \& Lopez, S. (2009). Psicologia Positiva. Porto Alegre: Artmed.

Stahl, G. \& Caligiuri, P. (2005). The effectiveness of expatriate coping strategies: the moderating role of cultural distance, position level, and time on the international assignment. Journal of Applied Psychology, 90(4), 603-615.

Steel, P., Schmidt, J., \& Schultz, J. (2008). Refining the relationship between personality and subjective well-being. Psychological Bulletin, 134(1), 138-161.

Terris, M. (1975). Approaches to an epidemiology of health. The American Journal of Public Health, 65(10), 1037-1045.

Vermunt, R., Spaans, E., \& Zorge, F. (1989). Satisfaction, happiness and well-being of dutch students. Social Indicators Research, 21(1), 1-33.

Watson, D. (2005). Positive affectivity: the disposition to experience pleasurable emotional states. In: Snyder, C., \& Lopez, S. Handbook of positive psychology. New York: Oxford University Press.

Woyciekoski, C., Stenert, F., \& Hutz, C. (2012). Determinantes do bem-estar subjetivo. Psico, 43(3), 280-288.

Zamberlam, J., Corso, G., Cimadon, J., \& Bocchi, L. (2014). Os novos rostos da imigração no Brasil - Haitianos no Rio Grande do Sul. Porto Alegre: Solidus.

Zanon, C., \& Hutz, C. (2010). Relações entre bem-estar subjetivo, neuroticismo, ruminação, reflexão e sexo. Gerais: Revista Interinstitucional de Psicologia, 2(2), 118-127. 